\title{
Novel route for Synthesis of Antihypertensive activity of Tetrazole analogues as a Carbamate and Urea Derivatives
}

\author{
Ramakrishna Vellalacheruvu ${ }^{1,2 *}$, R Sai Leela ${ }^{3}$ and L K Ravindranath ${ }^{1}$ \\ ${ }^{1}$ Department in Chemistry, SK University, India \\ ${ }^{2}$ GVK Bio Science Pvt Ltd., IDA, India \\ ${ }^{3}$ SK University, India
}

Submission: August 21, 2017; Published: March 01, 2018

*Corresponding author: Ramakrishna Vellalacheruvu, Department of Chemistry, SK University, India, Tel: 9493268448; Email: vellalacheruv@gmail.com

\begin{abstract}
The Novel route was developed for synthesis of high potential tetrazole carbamate and urea derivatives by using conventional methods. (trifluoromethyl)phenyl)quinoline-5-carboxamide (3) was converted into chloroamidine derivative by using POCl3 and DMF (cat), then treated with sodium azide by [3+2] cycloaddition to give 8-(benzyloxy)-5-(1-(4-(trifluoromethyl)phenyl)-1H-tetrazol-5-yl) quinoline (5). The tetrazolidine compound was debenzylated, then Alkylation with Ethyl Bromo acetate and converted to acid (8) by hydrolysis with LiOH. The acid was converted to acid azide by using DPPA, and then Treated with Alcohols and Amine to give substituted Carbamates and urea derivatives by using Curtius rearrangement.
\end{abstract}

Keywords: Tetrazolidine; Diphenyl phosphoryl azide; [3+2] Cycloaddition reaction; Curties re-arrangement; Combi-flash chromatography

Abbreviations: API: Active Pharmaceutical Drug Intermediates; SSNRIs: Selective Serotonin and Nor Epinephrine Reuptake Inhibitors; ABDD: Analogue-Based Drug Discovery; RAS: Renin Angiotensin System

\section{Introduction}

Tetrazole analogues have a potential pharmacological activity in medicinal chemistry division. Several Active pharmaceutical drug intermediates (API) of tetrazole derivatives played their role in pharmaceutical and agrochemical region. These compounds act as multidimensional biological active drug candidates such as inhibition of Angiotensin ( $\left.\mathrm{AT}_{1}\right)$, Angiotensin $\left(\mathrm{AT}_{2}\right)$ receptor (Hypertension), antifungal \& antibacterial, corrosion inhibitor, anti-inflammatory, anticancer, antioxidant, antifungal, analgesic, Antiviral, protein-arginine deiminase inhibitor, antimicrobial, Anti allergic, dual Selective serotonin and Nor epinephrine Reuptake inhibitors (SSNRIs) and HIV inhibitors. When Drug model designing, tetrazole nucleolus consider as a co-sister of carboxylic acid and amide derivatives [1-12]. The pka value of tetrazole is correlated with amide and acid functional groups. The introduction of tetrazole ring in drug substrate prominently increases their bio-availability and prolonging biological action and also avoids acute toxicity of drug. In Analogue-based drug discovery (ABDD), introduce tetrazole nucleolus as an important descriptor. Several research works is progress based on synthesis of tetrazole amino acid analogues, and nucleotide and nucleoside analogues instead of acid and amide functional group.

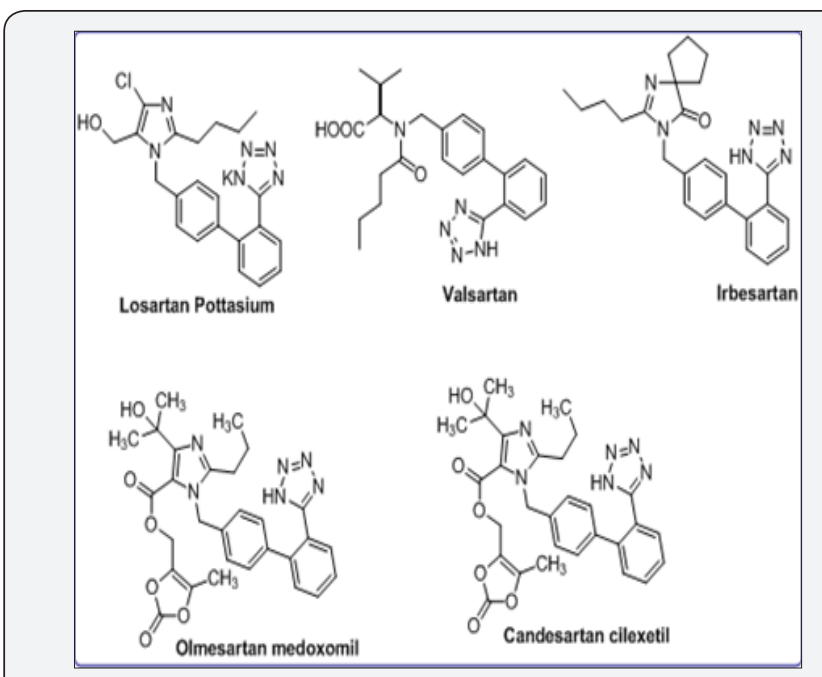

Figure 1: List of ACE inhibitors as an anti hypertensive drugs. 
Many Tetrazole analogs were available for treatment of hypertension, such as Losartan potassium, Valsartan, Irbesartan, Candesartan and Olmesartan medoxonil. These drugs played a vital role to inhibit Angiotensin converting enzyme. They block $\mathrm{AT}_{1} \& \mathrm{AT}_{2}$ receptors which is located in kidney, heart, vascular smooth muscle cells, brain, and adrenal glands. The renin angiotensin system (RAS) is a powerful regulator of Blood pressure. These drugs block renin-angiotensin system (RAS, enzyme) which is secretly produced in Kidney. Such few antihypertension drugs were described in Figure 1.
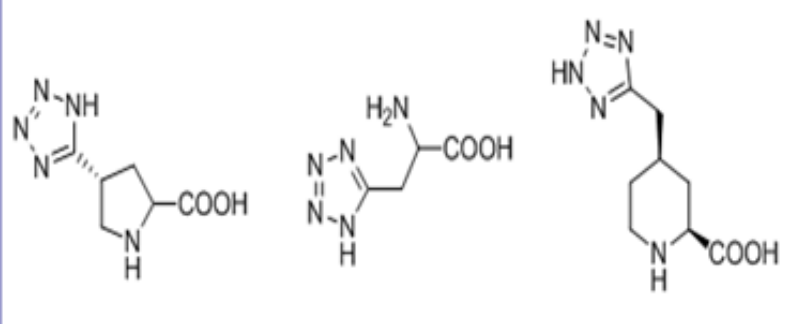

Figure 2: metabolically bioisostere for carboxy and amide functional groups.

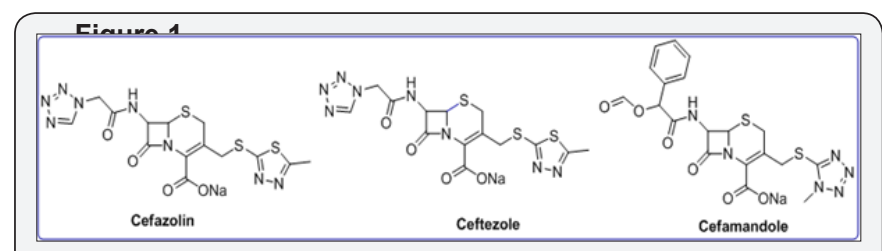

Figure 3: Generation of Cephalosporin Antibiotics.

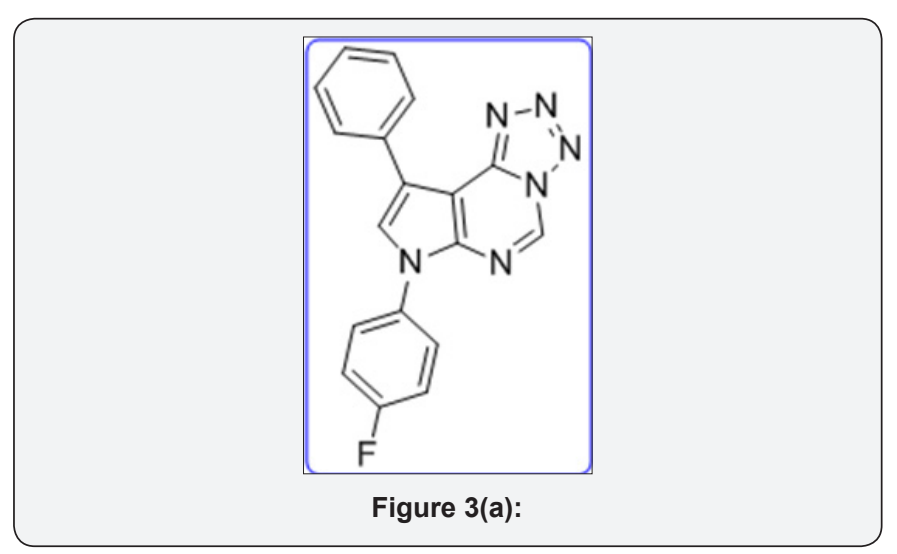

Tetrazole ring was widely used as a metabolically stable bioisostere for carboxy and amide functional groups in molecular design and synthesis of modified amino acids. Such analogs are described in Figure 2. The generations of Cephalosporin Antibiotics played a vital role in diagnosis process. Huge research work has been done for development of these drug analogs shown in Figure 3. Dave CG shah and coworkers synthesized 7,9-Disubstituted-7H-tetrazolo[1,5-c] pyrrolo[3,2-e] pyrimidines and evaluated their biological activity. Below compound exhibited better activity than ampicillin against all tested culture (Figure 3a). Venkataraman $\mathrm{S}$ et al. [10] developed a novel route for terazole analgous of $\mathrm{Cl}$ Amidines and F- Amidines (Figure 3b). As a part of our research work, we synthesized a high potential tetrazolidine analogous were synthesized as a urea and carbamate derivatives using conventional methods of cycloaddition reactions and curtius rearrangement reactions. Present method we avoid toxic and hazard reagents during synthesis of urea and carbamate derivatives.

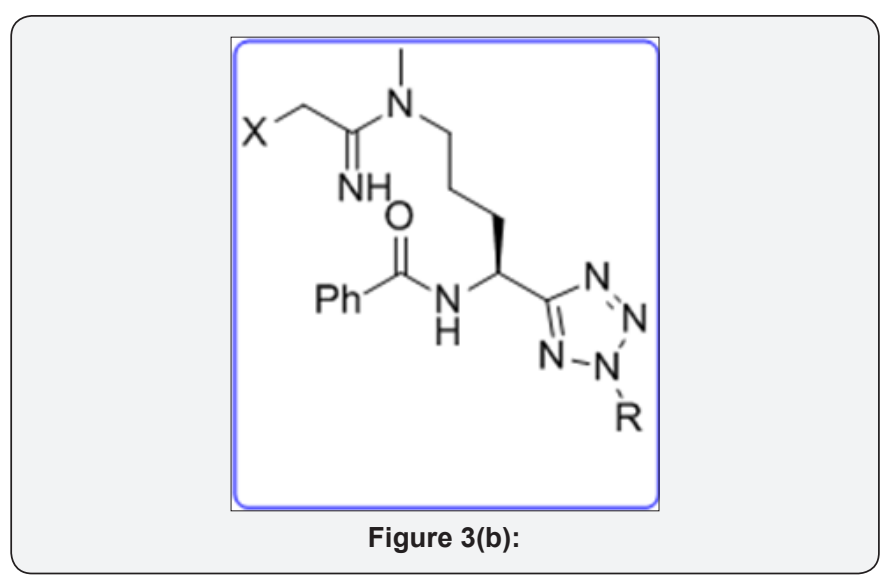

\section{Materials and Methods}

All Amines and alcohols and Reagents collected from commercial sources (Aldrich, Alfa Aesar). THF and Toluene were thoroughly dried using sodium metal and benzophenone before conduct reaction. DMF was dried using $\mathrm{CaH}$. Alcohols (EtOH, MeOH) were super dried using Grignard method (Mg, I2). The Curtius rearrangement reactions were conducted in sealed tube. These derivatives were characterized by using Analytical methods like IR, NMR (400mHz, Bruker). The melting points were recorded using on a WRS-1A Digital Melting Point Apparatus without correction. Infrared spectra were taken using an AVATAR 370 FT-IR spectrometer. ${ }^{1} \mathrm{H}$ NMR, ${ }^{13} \mathrm{C}$ NMR spectra were recorded with a Bruker spectrometer operating at $400 \mathrm{MHz}$ used as a trimethylsilane as a reference and values were recorded in ppm. The progress of reaction was monitored using TLC system and $\mathrm{I}_{2}$ spray and $\mathrm{KMnO}_{4}$ TLC strain. The crude compounds were purified using column chromatography (100-200 mesh silica) and Combi-flash chromatography. The hydrogenation process was carried out using parr shaker.

\section{Objective of this research}

Present work is corresponding to develop novel synthetic route for preparation of the quinoline attached tetrazolidine urea and $\mathrm{N}$-carbamate derivatives and characterized by IR and ${ }^{1} \mathrm{HNMR}$.

\section{Experimental Methods}

In this research work, we prepared below compounds and mentioned in step wise manner. The detailed scheme was given in Scheme 1. The Reaction mechanism for step 4 was mentioned. 
o Step-1: 8-(benzyloxy)quinoline-5-carboxylic acid (2)

o Step-2: 8-(benzyloxy)-N-(4-(trifluoromethyl)phenyl) quinoline-5-carboxamide (3)

o Step-3: (E)-8-(benzyloxy)-N-(4-(trifluoromethyl) phenyl) quinoline-5-carbimidoyl chloride (4)

o Step-4: 8-(benzyloxy)-5-(1-(4-(trifluoromethyl) phenyl)-1H-tetrazol-5-yl)quinoline (5)

o Step-5: 5-(1-(4-(trifluoromethyl)phenyl)-1H-tetrazol5-yl) quinolin-8-ol (6)

o Step-6: Ethyl-2-((5-(1-(4-(trifluoromethyl)phenyl)1H-tetrazol-5-yl)quinolin-8-yl)oxy)acetate (7) o Step 7: 2-((5-(1-(4-(trifluoromethyl)phenyl)-1Htetrazol-5-yl)quinolin-8-yl)oxy)acetic acid (8)

o Step 8: 2-((5-(1-(4-(trifluoromethyl)phenyl)-1Htetrazol-5-yl) quinolin-8-yl)oxy)acetylazide (9)

o $\quad$ Step 9: Substituted(c(5-(1-(4-(trifluoromethyl) phenyl)-1H-tetrazol-5-yl)quinolin-8-yl)oxy)methyl) carbamate (10 a-e)

o Step 10: substituted-3-(((5-(1-(4-(trifluoromethyl) phenyl)-1H-tetrazol-5-yl)quinolin-8-yl)oxy)methyl)urea (11 a-e)

\section{Scheme 1: (Figure 3c)}

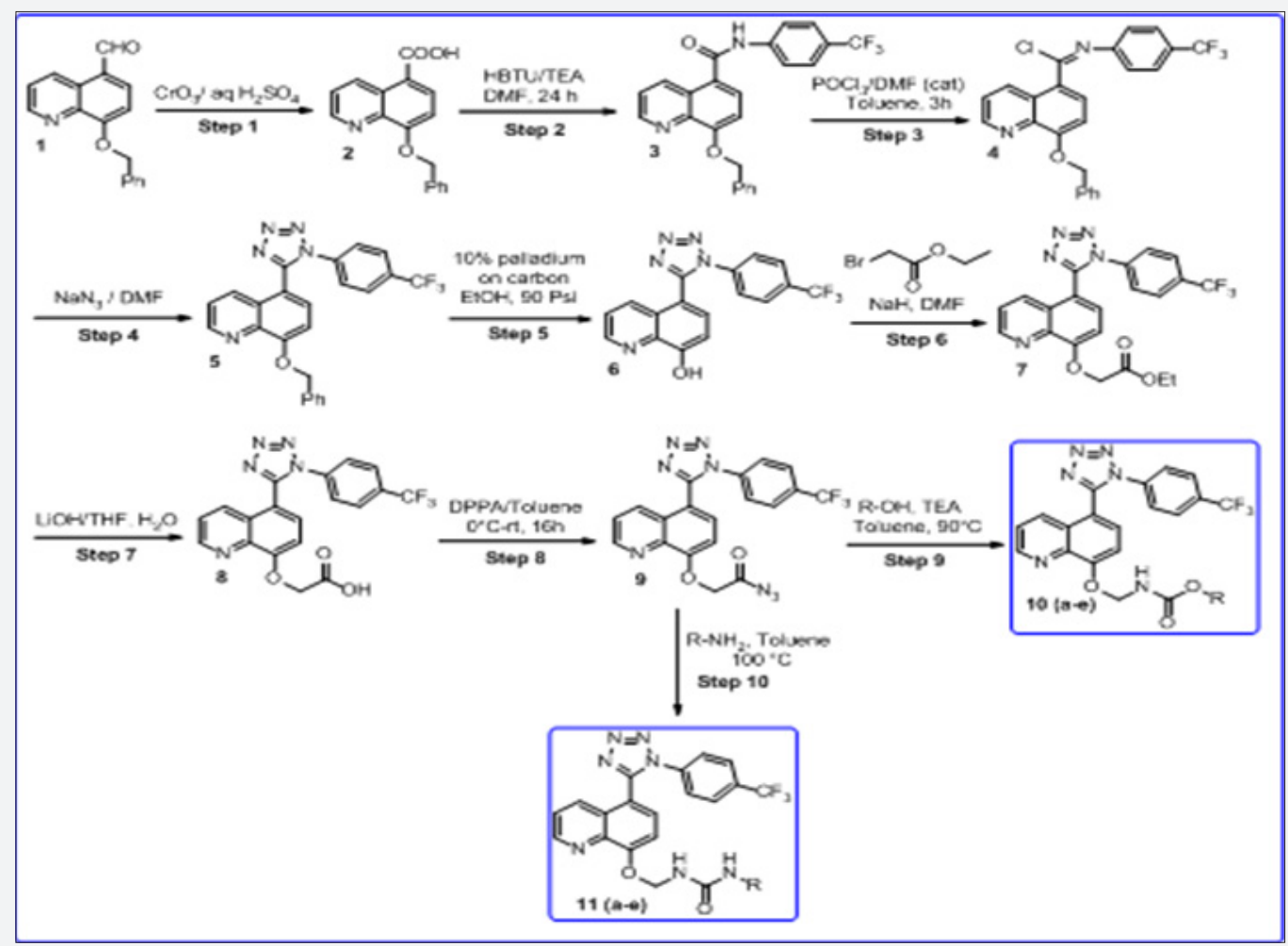

Figure 3(c):

\section{Reaction Conditions:}

Step 1: $\mathrm{CrO}_{3} / \mathrm{H}_{2} \mathrm{SO}_{4}, 0{ }^{\circ} \mathrm{C}, 3 \mathrm{~h}$,

Step 2: HBTU /DIPEA (3eq), DMF. Rt, $16 \mathrm{~h}$

Step 3: $\mathrm{POCl}_{3} / \mathrm{DMF}$ (cat), $0{ }^{\circ} \mathrm{C}-50{ }^{\circ} \mathrm{C}, 3 \mathrm{~h}$

Step 4: $\mathrm{NaN}_{3} / \mathrm{DMF}, 80^{\circ} \mathrm{C}, 4 \mathrm{~h}$

Step 5: 10\% Palladium on Carbon, $\mathrm{H}_{2} / 90$ psi

Step 6: Ethyl Bromo Acetate, $\mathrm{NaH}, 0^{\circ} \mathrm{C}-\mathrm{RT}$, $6 \mathrm{~h}$

Step 7: $\mathrm{LiOH}, \mathrm{THF} / \mathrm{H}_{2} \mathrm{O}$ (1:4), $16 \mathrm{~h}$

Step 8: DPPA / Toluene, $0{ }^{\circ} \mathrm{C}, 8 \mathrm{~h}$

Step 9: R-OH, Toluene, $90^{\circ} \mathrm{C}, 5 \mathrm{~h}$, Sealed tube [13-22].

\section{Reaction mechanism for Step 2: (Figure 4)}

Step 1: 8-(benzyloxy) quinoline-5-carboxylic acid (2): (Figure 4a)

Zones Reagent: In a 1 lit 3 neck round bottom flask fitted with mechanical stirrer, $\mathrm{CrO}_{3}(28 \mathrm{~g}, 0.285 \mathrm{~mol})$ was dissolve in water $(50 \mathrm{~mL})$ and cooled to $0{ }^{\circ} \mathrm{C}$ for $10 \mathrm{~min}$. Then added $\mathrm{H}_{2} \mathrm{SO}_{4}$ $(5.5 \mathrm{M}, 130 \mathrm{~mL}, 0.3 \mathrm{eq})$ drop wise for $30 \mathrm{~min}$ at $-5^{\circ} \mathrm{C}$. The reaction mixture was stirred for $10 \mathrm{~min}$. In Another RBF 8-(benzyloxy) quinoline-5-carbaldehyde $(25 \mathrm{~g}, 0.09 \mathrm{~mol})$ was dissolve in Acetone $(250 \mathrm{~mL})$ and cooled to $0{ }^{\circ} \mathrm{C}$. The above reagent (Zones reagent) was added drop wise for $1 \mathrm{~h}$ and stirred for $2 \mathrm{~h}$. The progress of reaction was monitored by TLC. After completion, Reaction 
mixture was poured in ice cold water and stirred for $30 \mathrm{~min}$. The reaction mixture was extracted with EtOAc $(3 \times 250 \mathrm{~mL})$. The reaction mixture was filtered on celite bed. The organic layer were separated and dried over anhydrous $\mathrm{Na}_{2} \mathrm{SO}_{4}$, filtered and evaporated under vacuum to give black crude product. The crude was purified by column chromatography (100-200 mesh silica, Eluent: Pure EtOAc) isolated 8-(benzyloxy) quinoline5-carboxylic acid (15g, Yield: 57\%) as a white solid. M.P. 282$285^{\circ} \mathrm{C}$. IR (KBr, cm${ }^{-1}$ ): 3400, 3010, 1710, 1580, 1440, 770, 655. ${ }^{1} \mathrm{HNMR}\left(d_{6}\right.$-DMSO, $\left.400 \mathrm{mHz}\right): 4.9(\mathrm{~s}, 1 \mathrm{H}), 7.35-7.5(\mathrm{~m}, 5 \mathrm{H}), 7.8(\mathrm{t}$, $1 \mathrm{H}), 8.4(\mathrm{~d}, 1 \mathrm{H}), 8.9(\mathrm{~d}, 1 \mathrm{H}), 9.5(\mathrm{~d}, 1 \mathrm{H}), 10.2$ (brs, 1H).
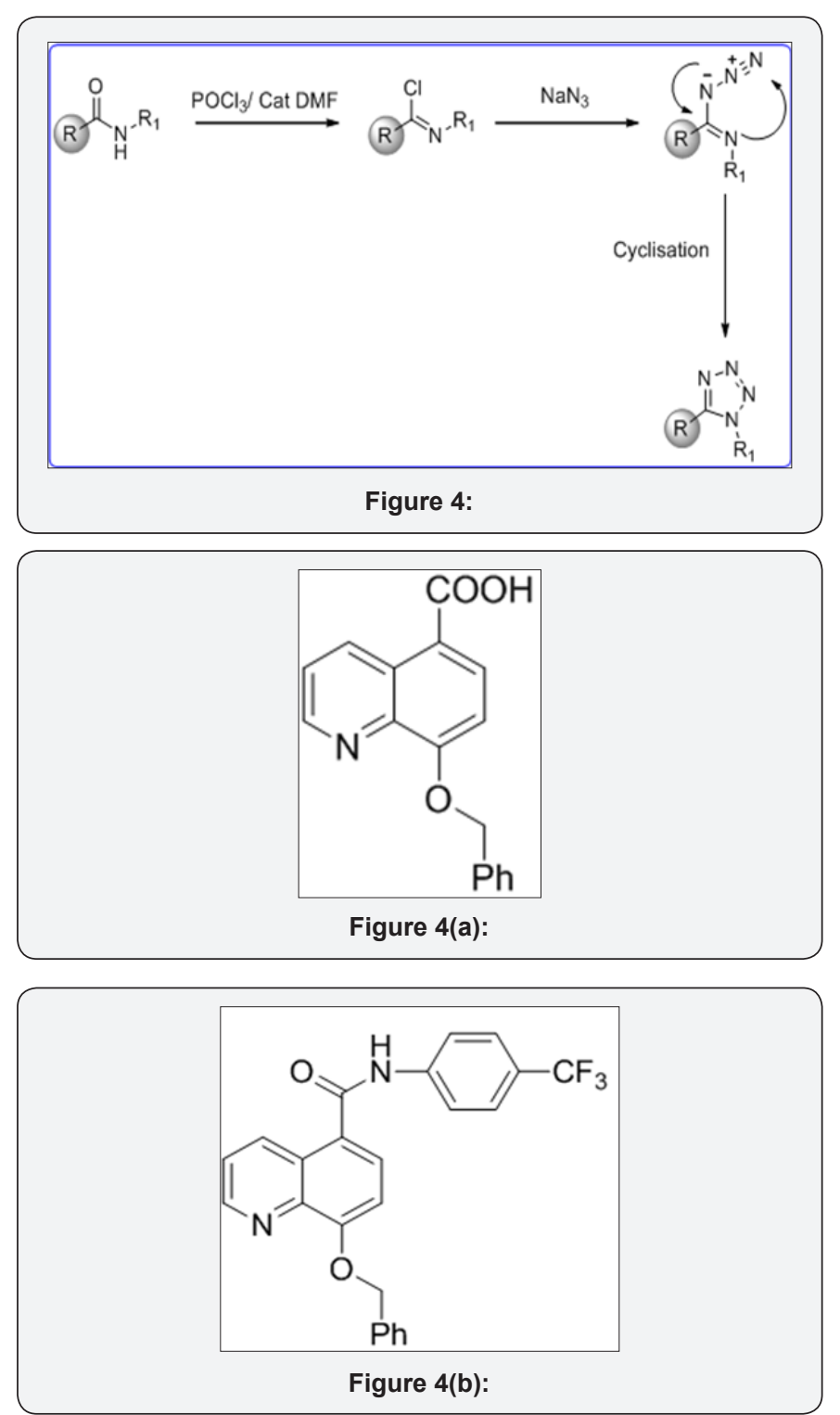

Step 2: 8-(benzyloxy)-N-(4-(trifluoromethyl)phenyl) quinoline-5-carboxamide (3): (Figure 4b)

To a mixture of 8-(benzyloxy)quinoline-5-carboxylic acid (15g, 0.053mol), 4-(trifluoromethyl) aniline $(8.6 \mathrm{~g}, 0.053 \mathrm{~mol})$ in DMF $(100 \mathrm{~mL})$ was added Di-isopropyl ethyl amine (DIPEA) $(25 \mathrm{~mL}, 0.159 \mathrm{~mol})$ and cooled to $0^{\circ} \mathrm{C}$. Then HBTU $(22 \mathrm{~g}, 0.06 \mathrm{~mol})$ was added and stirred at room temperature for $16 \mathrm{~h}$. The progress of reaction was monitored by TLC and iodine strain. After completion, reaction mixture was poured in ice cold water $(300 \mathrm{~mL})$ and extracted with EtOAc $(3 \times 300 \mathrm{~mL})$. The organic layer was separated and washed with brine solution $(100 \mathrm{~mL})$. The organic layer was collected and dried over anhydrous $\mathrm{Na}_{2} \mathrm{SO}_{4}$, filtered and evaporated under vacuum to give crude residue. The crude product was purified by Combi-flash column chromatography (230-400 meshsilica, Eluent: 10\% MeOH$\mathrm{CHCl}_{3}$ ) isolated 8-(benzyloxy)-N-(4-(trifluoromethyl)phenyl) quinoline-5-carboxamide (3) (16g, yield: $72 \%$ ) as a white solid. M.p: $352-355^{\circ} \mathrm{C}$. IR (KBr, cm-1): 3410, 3020, 1700, 1610, 1320, 1420, 780, 685. 1HNMR ( $d_{6}$-DMSO, $\left.400 \mathrm{mHz}\right): 5.1(\mathrm{~s}, 2 \mathrm{H}), 7.2(\mathrm{~d}$, $1 \mathrm{H}), 7.38-7.5(\mathrm{~m}, 5 \mathrm{H}), 7.6(\mathrm{~d}, 2 \mathrm{H}), 7.63(\mathrm{~d}, 2 \mathrm{H}), 7.83(\mathrm{t}, 1 \mathrm{H}), 8.8$ (br, 2H), $9.5(\mathrm{~d}, 1 \mathrm{H})$.

\section{Step 3: (E)-8-(benzyloxy)-N-(4-(trifluoromethyl) phenyl)quinoline-5-carbimidoyl chloride (4): (Figure 4c)}

8-(benzyloxy)-N-(4-(trifluoromethyl)phenyl)quinoline-5carboxamide (3) (15g, $0.035 \mathrm{~mol})$ in $\mathrm{POCl} 3(150 \mathrm{~mL})$ was cooled to $0{ }^{\circ} \mathrm{C}$. Then added DMF (cat, $1 \mathrm{~mL}$ ) drop wise and stirred at room temperature for $1 \mathrm{~h}$. The reaction mixture was heated at $60{ }^{\circ} \mathrm{C}$ for $3 \mathrm{~h}$. The progress of reaction was monitored by TLC. After completion, reaction mixture was cooled to room temperature. The $\mathrm{POCl}_{3}$ was evaporated under high vacuum to give crude residue. The residue was co-distilled with dry toluene $(2 \times 100 \mathrm{ml})$ to give crude product. The crude was carried to next step without further purification. This compound data was not analyzed.

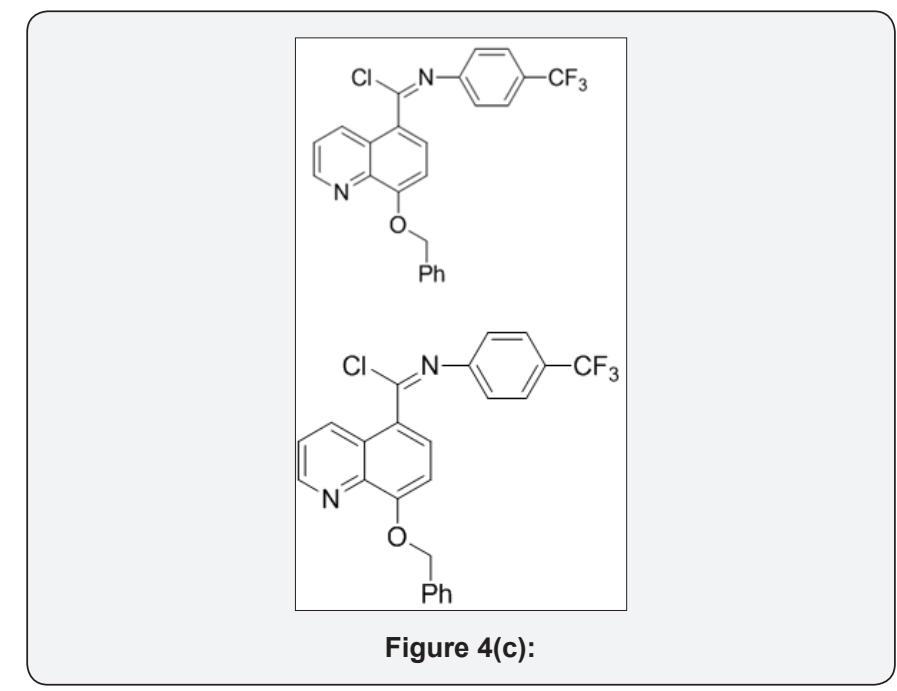

\section{Step 4: 8-(benzyloxy)-5-(1-(4-(trifluoromethyl)} phenyl)-1H-tetrazol-5-yl)quinoline (5): (Figure 4d)

(E)-8-(benzyloxy)-N-(4-(trifluoromethyl)phenyl)quinoline5-carbimidoyl chloride (4) (15g, 0.035mol) in dry DMF $(70 \mathrm{~mL})$ was cooled to $0{ }^{\circ} \mathrm{C}$. Then sodium azide (3eq) was added portionwise and stirred at room temperature for $1 \mathrm{~h}$. After that, Reaction mixture was heated at $80^{\circ} \mathrm{C}$ for $4 \mathrm{~h}$. The progress of 
reaction was monitored by TLC. After completion, reaction mixture was cooled to $0^{\circ} \mathrm{C}$ and poured in ice cold water $(200 \mathrm{~mL})$ and basified up to $\mathrm{P}_{-}-8$ with sat. aq. $\mathrm{NaHCO}_{3}$ sol. The aqueous layer was extracted with EtOAc $(3 \times 100 \mathrm{~mL})$. The organic layer were collected and dried over anhydrous $\mathrm{Na}_{2} \mathrm{SO}_{4}$, filtered and evaporated under vacuum to give crude product. The crude was purified by column chromatography (100-200 mesh silica, Eluent: 50\% EtOAc-Pet Ether) isolated 8-(benzyloxy)-5-(1-(4(trifluoromethyl)phenyl)-1H-tetrazol-5-yl) quinoline (5) (8g, Yieild: $50 \%$ ) as a pale yellow solid. M.p: $280-282^{\circ} \mathrm{C}$. IR (KBr, cm $\left.{ }^{1}\right)$ : 3010, 1550, 1510, 820, $655{ }^{1} \mathrm{HNMR}\left(d_{6}\right.$-DMSO, 400mHz): 5.10 (s, 2H), $7.1(\mathrm{~d}, 1 \mathrm{H}), 7.4-7.68(\mathrm{~m}, 11 \mathrm{H}), 8.4(\mathrm{~d}, 1 \mathrm{H}), 8.78(\mathrm{~d}, 1 \mathrm{H})$.

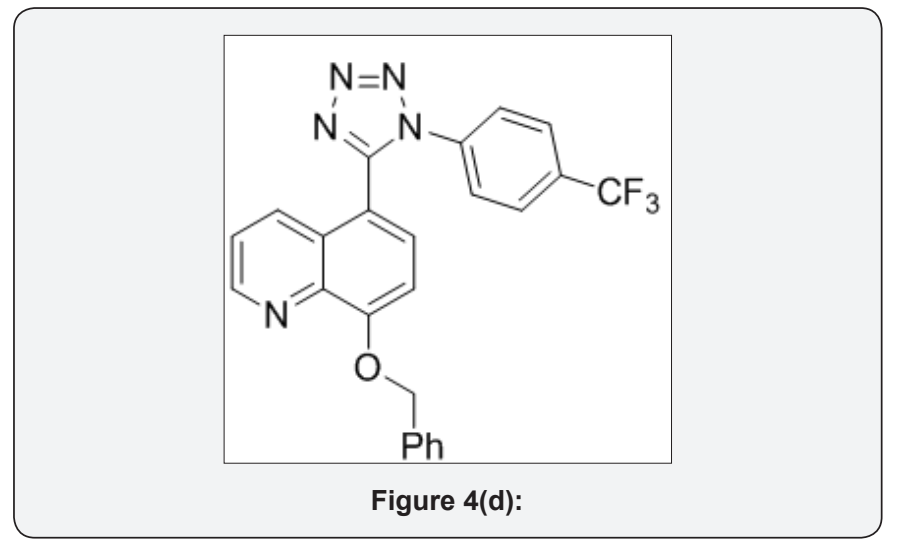

Step 5: 5-(1-(4-(trifluoromethyl)phenyl)-1H-tetrazol5-yl)quinolin-8-ol (5): (Figure 4e)

8-(benzyloxy)-5-(1-(4-(trifluoromethyl)phenyl)-1Htetrazol-5-yl)quinoline (5) $(8 \mathrm{~g}, 0.012 \mathrm{~mol})$ in $\mathrm{MeOH}(100 \mathrm{~mL})$ was added $10 \%$ palladium on carbon and TFA $(10 \mathrm{~mL})$ and hydrogenated at 80 Psi using parr shaker for $5 \mathrm{~h}$ at room temperature. The progress of reaction was monitored by TLC. After completion, Reaction mixture was filtered on cellite bed and washed with $\mathrm{MeOH}(2 \times 50 \mathrm{~mL})$. The organic layer was collected and evaporated under vacuum to give crude residue. The residue was purified by combi-flash column chromatography isolated 5-(1-(4-(trifluoromethyl)phenyl)-1H-tetrazol-5-yl) quinolin8-ol (6) (5.5g, Yield: 88\%). as a white solid.M.p: $310-315^{\circ} \mathrm{C}$. IR $\left(\mathrm{KBr}, \mathrm{cm}^{-1}\right): 3300,3040,1580,1425,1150,760,691,{ }^{1} \mathrm{HNMR}\left(d_{6}{ }^{-}\right.$ DMSO, $400 \mathrm{mHz}): 7.2(\mathrm{~d}, 1 \mathrm{H}), 7.5-7.62(\mathrm{~m}, 5 \mathrm{H}), 7.8(\mathrm{~d}, 1 \mathrm{H}), 8.4(\mathrm{~d}$, $1 \mathrm{H}), 8.88(\mathrm{~d}, 1 \mathrm{H}) .10 .1$ (brs, 1H).

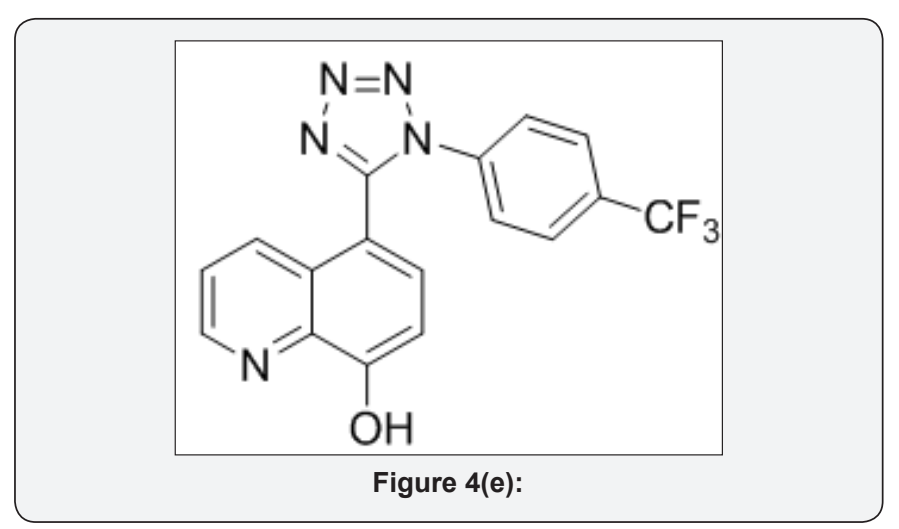

Step 6: Ethyl 2-((5-(1-(4-(trifluoromethyl)phenyl)-1Htetrazol-5-yl)quinolin-8-yl)oxy)acetate (7): (Figure 4f)

To a solution 5-(1-(4-(trifluoromethyl)phenyl)-1H-tetrazol5-yl)quinolin-8-ol (6) (5g, 0.014mol), in DMF ( $50 \mathrm{~mL})$ was cooled to $0^{\circ} \mathrm{C}$. Then added sodium hydride $(1.7 \mathrm{~g}, 0.042 \mathrm{~mol}$, 3eq) portion wise and stirred for $30 \mathrm{~min}$. To that Ethyl bromo acetate $(1.71 \mathrm{~mL}$, $0.0154 \mathrm{~mol}$ ) was added drop wise and stirred for $6 \mathrm{~h}$ at room temperature. The progress of reaction was monitored by TLC. After completion, reaction mixture was poured in ice cold water $(100 \mathrm{~mL})$ and basified with aq $\mathrm{Na}_{2} \mathrm{CO}_{3}$ up to $\mathrm{PH}-8$ and extracted with EtOAc $(2 \times 10 \mathrm{~mL})$. The organic layer were separated and washed with brine $(25 \mathrm{~mL})$, and dried over anhydrous $\mathrm{Na}_{2} \mathrm{SO}_{4}$, filtered and evaporated under vacuum to give crude product. The crude was purified by column chromatography (100200 mesh silica, Eluent: 60\% EtOAc- Pet ether) isolated ethyl 2-((5-(1-(4-(trifluoromethyl)phenyl)-1H-tetrazol-5-yl)quinolin8-yl)oxy)acetate (4g, Yield: $64 \%$ ) as a semi brown colour liquid. M.p: $255-258{ }^{\circ} \mathrm{C}$. IR $\left(\mathrm{KBr}, \mathrm{cm}^{-1}\right)$ : 3040, 1640, 1560, 1440, 1130, 780, 698, 1HNMR ( $d_{6}$-DMSO, 400mHz): $1.4(\mathrm{t}, 3 \mathrm{H}), 3.8(\mathrm{q}, 2 \mathrm{H})$, $4.8(\mathrm{~s}, 2 \mathrm{H}), 7.23(\mathrm{~d}, 1 \mathrm{H}), 7.5-7.62(\mathrm{~m}, 5 \mathrm{H}), 7.75(\mathrm{~d}, 1 \mathrm{H}), 8.39(\mathrm{~d}$, $1 \mathrm{H}), 8.7(\mathrm{~d}, 1 \mathrm{H})$.

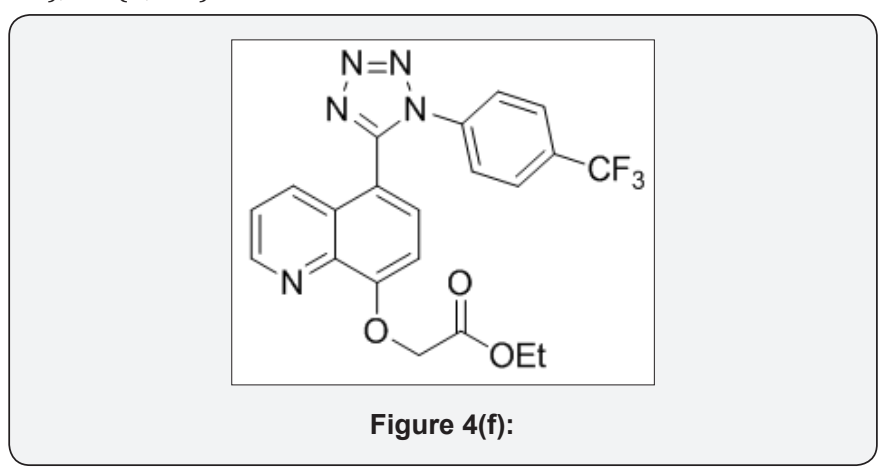

Step 7: 2-((5-(1-(4-(trifluoromethyl)phenyl)-1Htetrazol-5-yl)quinolin-8-yl)oxy)acetic acid (8): (Figure 4g)

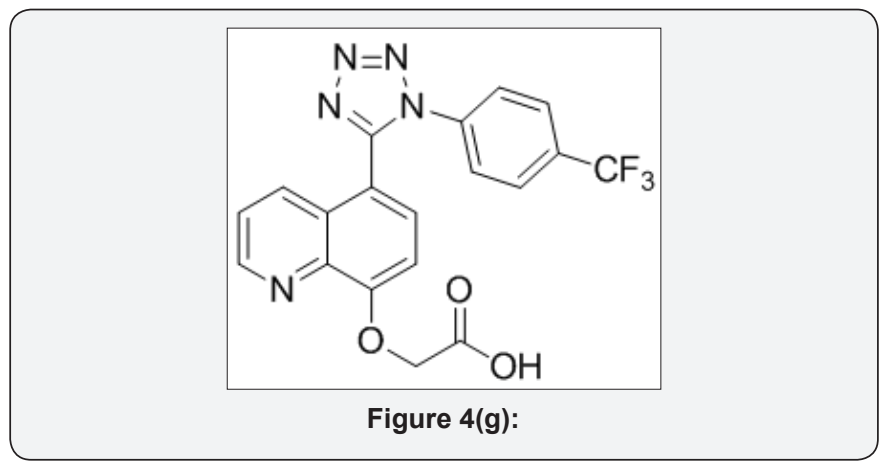

Ethyl 2-((5-(1-(4-(trifluoromethyl)phenyl)-1H-tetrazol5 -yl)quinolin-8-yl)oxy)acetate (8) (4g, $0.009 \mathrm{~mol})$ in THF/ $\mathrm{H}_{2} \mathrm{O}(40 \mathrm{~mL} / 10 \mathrm{~mL}, 4: 1)$ was added $\mathrm{LiOH}$ (4eq) and stirred at room temperature for $16 \mathrm{~h}$. The progress of reaction was monitored by TLC. After completion, reaction mixture was 
poured in ice cold water $(100 \mathrm{~mL})$ and acidified with aq $\mathrm{NaHSO}_{3}$ $(100 \mathrm{~mL})$ up to PH-4 and extracted with EtOAc $(3 \times 00 \mathrm{~mL})$. The organic layer were collected and dried over anhydrous $\mathrm{Na} 2 \mathrm{SO} 4$, filtered and evaporated under vacuum to give crude product. The crude was purified by column chromatography (100-200 mesh silica, Eluent: 80\% EtOAc- Pet ether) isolated 2-((5-(1-(4-(trifluoromethyl)phenyl)-1H-tetrazol-5-yl)quinolin8-yl)oxy)acetic acid (3.5,Yield: 93\%) as a white solid. M.p: 285$288^{\circ} \mathrm{C}$. IR (KBr, cm$\left.{ }^{-1}\right): 3500,3030,1690,1560,1440,760,610$, ${ }^{1}$ HNMR $\left(d_{6}\right.$-DMSO, $\left.400 \mathrm{mHz}\right): 4.8(\mathrm{~s}, 2 \mathrm{H}), 7.3(\mathrm{~d}, 1 \mathrm{H}), 7.5-7.65(\mathrm{~m}$, $5 \mathrm{H}), 7.78(\mathrm{~d}, 1 \mathrm{H}), 8.38(\mathrm{~d}, 1 \mathrm{H}), 8.8(\mathrm{~d}, 1 \mathrm{H}), 10.4$ (brs, 1H).

\section{Step 8: 2-((5-(1-(4-(trifluoromethyl)phenyl)-1H- tetrazol-5-yl)quinolin-8-yl)oxy)acetyl azide (9): (Figure 4h)}

To a solution of 2-((5-(1-(4-(trifluoromethyl)phenyl)-1Htetrazol-5-yl)quinolin-8-yl)oxy) acetic acid (3.5g, $0.008 \mathrm{~mol})$ in toluene $(35 \mathrm{~mL})$ was added DPPA $(2.25 \mathrm{~mL}, 0.014 \mathrm{~mol})$ at $0{ }^{\circ} \mathrm{C}$ and stirred at room temperature for $8 \mathrm{~h}$. The progress of reaction was monitored by TLC. After completion, reaction mixture was evaporated under vacuum to give crude residue. The crude residue was co-distilled with Toluene $(2 \times 30 \mathrm{~mL})$ isolated 2-((5-(1-(4-(trifluoromethyl)phenyl)-1H-tetrazol-5-yl)quinolin8-yl)oxy)acetyl azide (4.5g) as a liquid. The crude residue was carried to next step without further purification.

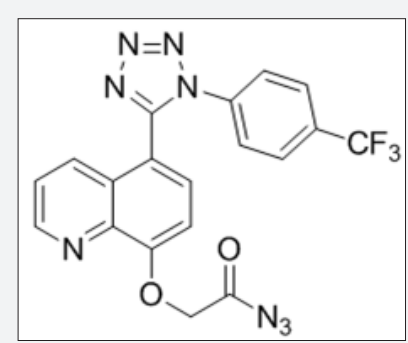

Figure 4(h):

Step 9: Substituted (((5-(1-(4-(trifluoromethyl) phenyl)-1H-tetrazol-5-yl)quinolin-8-yl)oxy)methyl) carbamate (10): (Figure 4i)

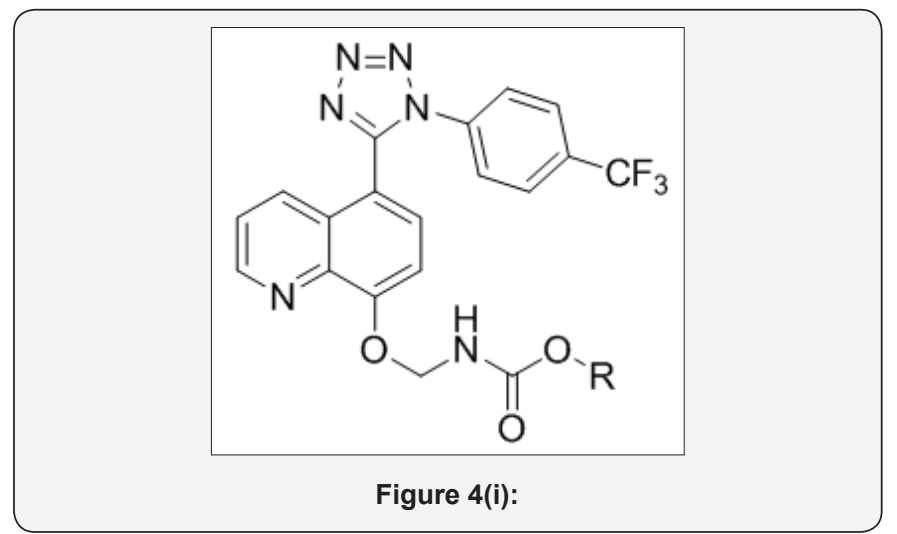

To a solution of 2-((5-(1-(4-(trifluoromethyl)phenyl)1H-tetrazol-5-yl)quinolin-8-yl)oxy)acetyl azide (9) (250mg, $0.568 \mathrm{mmol})$ in Dry toluene $(10 \mathrm{~mL})$ was added TEA $(1.7 \mathrm{mmol}$, 3eq), Alcohol (1.1eq) and heated at $100{ }^{\circ} \mathrm{C}$ for $5 \mathrm{~h}$ in sealed tube $(50 \mathrm{~mL})$. The progress of reaction was monitored by TLC. After completion, reaction was evaporated under vacuum to give crude product. The crude was purified by Combi-flash column chromatography (100-200 mesh silica, Eluent: 70\% EtOAc-Pet ether), isolated substituted (((5-(1-(4-(trifluoromethyl)phenyl)1H-tetrazol-5-yl)quino lin-8-yl)oxy)methyl)carbamate10 (a-e). The list of carbonate derivatives was given in Table 1.

Table 1: Summary data for $\mathrm{N}$-carbamate derivatives.

\begin{tabular}{|c|c|c|c|}
\hline $\begin{array}{c}\text { Compounds } \\
(\mathbf{1 0} \text { a-f })\end{array}$ & $\mathbf{R}$ & Reaction Time & Yield \\
\hline $10: 00 \mathrm{AM}$ & $\mathrm{Me}$ & $5 \mathrm{~h}$ & $40 \%$ \\
\hline $10 \mathrm{~b}$ & $\mathrm{Et}$ & $8 \mathrm{~h}$ & $55 \%$ \\
\hline $10 \mathrm{c}$ & ${ }^{\mathrm{t}} \mathrm{Bu}$ & $16 \mathrm{~h}$ & $60 \%$ \\
\hline $10 \mathrm{~d}$ & $\mathrm{Benzyl}$ & $10 \mathrm{~h}$ & $50 \%$ \\
\hline $10 \mathrm{e}$ & $\mathrm{MeO}-\mathrm{C}_{6} \mathrm{H}_{4}-\mathrm{CH}_{2}$ & $6 \mathrm{~h}$ & $65 \%$ \\
\hline
\end{tabular}

Methyl(( (5- (1 - (4-(trifluoromethyl)phenyl)-1 Htetrazol-5-yl)quinolin-8-yl)oxy)methyl) carbamate (10a): (Figure 4j)

M.p: $280-283^{\circ} \mathrm{C}$. IR (KBr, cm$\left.{ }^{-1}\right): 3450,3030,1645,1350,780$, 645, ${ }^{1} \mathrm{HNMR}\left(d_{6}-\mathrm{DMSO}, 400 \mathrm{mHz}\right): 3.5(\mathrm{~s}, 2 \mathrm{H}), 5.5(\mathrm{~s}, 2 \mathrm{H}), 7.2(\mathrm{~d}$, $1 \mathrm{H}), 7.5-7.64(\mathrm{~m}, 5 \mathrm{H}), 8.1(\mathrm{~m}, 3 \mathrm{H}), 8.4(\mathrm{~d}, 1 \mathrm{H}), 8.8(\mathrm{~d}, 1 \mathrm{H}) .{ }^{13} \mathrm{CNMR}$ $\left(d_{6}\right.$-DMSO, $\left.400 \mathrm{mHz}\right): 51,75,108,122,123,124.5,125,131,132$, $135,139,149,155,157,163$.

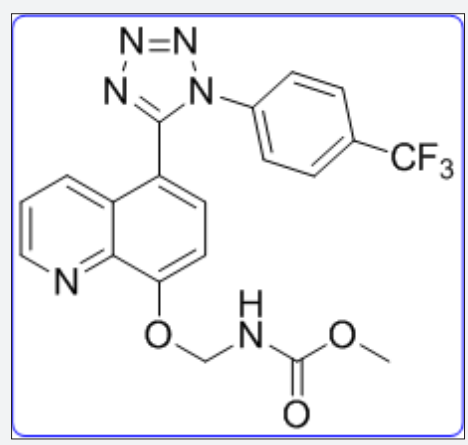

Figure 4(j):

Ethyl (((5-(1-(4-(trifluoromethyl)phenyl)-1H-tetrazol5-yl)quinolin-8-yl)oxy)methyl) carbamate (10b): (Figure 4k)

M.p: $290-293^{\circ} \mathrm{C} . \mathrm{IR}\left(\mathrm{KBr}, \mathrm{cm}^{-1}\right): 3450,3035,1650,1350,785$, 650, ${ }^{1} \mathrm{HNMR}\left(d_{6}\right.$-DMSO, $\left.400 \mathrm{mHz}\right): 1.25(\mathrm{t}, 3 \mathrm{H}), 4.2(\mathrm{q}, 2 \mathrm{H}), 5.4(\mathrm{~s}$, 2H), $7.2(\mathrm{~d}, 1 \mathrm{H})$ 7.55-7.63 (m, 5H), $7.9(\mathrm{~m}, 2 \mathrm{H}), 8.38(\mathrm{~d}, 1 \mathrm{H}), 8.85$ $(\mathrm{d}, 1 \mathrm{H}) \cdot{ }^{13} \mathrm{CNMR}\left(d_{6}\right.$-DMSO, $\left.400 \mathrm{mHz}\right): 15,62,77,107.5,122,123$, $124,125,131,132,135,140,150,155,156,164$. 


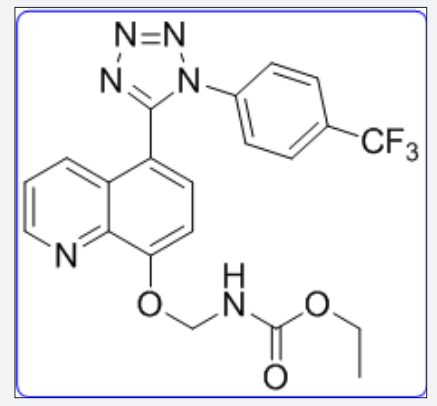

Figure 4(k):

Tert-butyl(((5-(1-(4-(trifluoromethyl)phenyl)-1Htetrazol-5-yl)quinolin-8-yl)oxy)methyl) carbamate (10c): (Figure 4l)

M.P: $250-253^{\circ} \mathrm{C}$, IR $\left(\mathrm{KBr}, \mathrm{cm}^{-1}\right): 3470,3040,1670,1380,770$, 640. ${ }^{1} \mathrm{HNMR}\left(d_{6}\right.$-DMSO, 400mHz): $1.5(\mathrm{~s}, 9 \mathrm{H}), 5.5(\mathrm{~s}, 2 \mathrm{H}), 7.18$ (d, 1H) 7.55-7.63 (m, 5H), $7.8(\mathrm{~m}, 2 \mathrm{H}), 8.37(\mathrm{~d}, 1 \mathrm{H}), 8.83(\mathrm{~d}, 1 \mathrm{H})$. ${ }^{13}$ CNMR $\left(d_{6}\right.$-DMSO, $\left.400 \mathrm{mHz}\right): 30,76,79,107,121,122.8,124.9$, $131,132,136,139,148,155,156,163.8$.

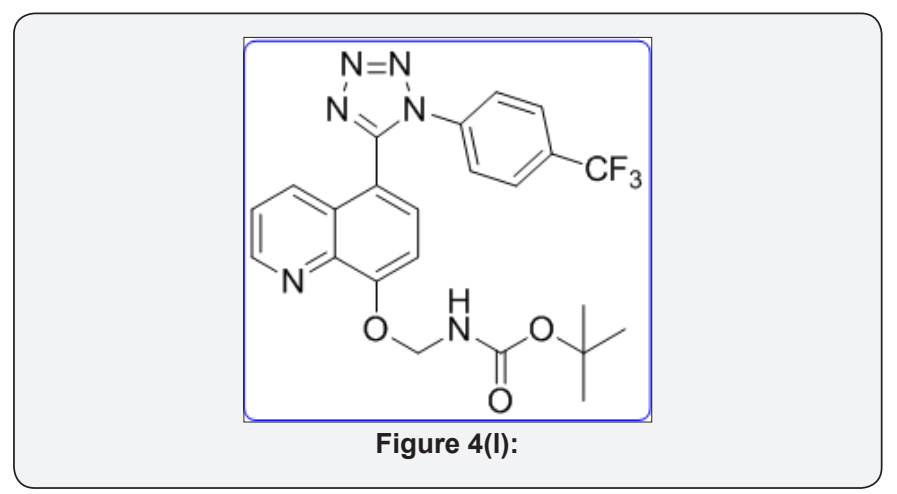

Benzyl ( ( 5 - (1 - (4 - (trifluoromethyl)phenyl) - 1 H tetrazol-5-yl)quinolin-8-yl)oxy)methyl) carbamate (10d): (Figure 4m)

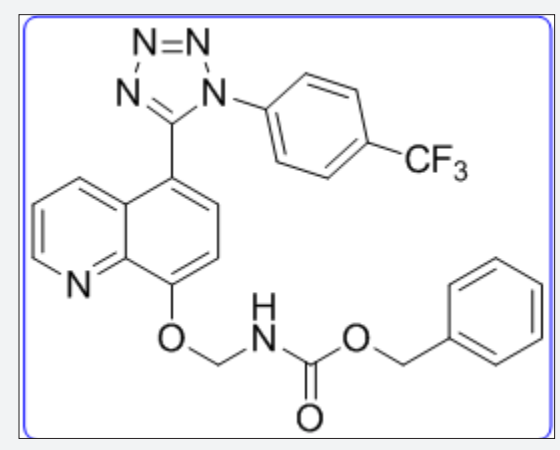

Figure 4(m):

M.p: $300-303^{\circ} \mathrm{C}$. IR (KBr, cm$\left.{ }^{-1}\right): 3490,3030,1650,1380,780$, 660. ${ }^{1} \mathrm{HNMR}\left(d_{6}\right.$-DMSO, $\left.400 \mathrm{mHz}\right): 5.1(\mathrm{~s}, 2 \mathrm{H}), 5.6(\mathrm{~s}, 2 \mathrm{H}), 7.2(\mathrm{~d}$, 1H) 7.55-7.63 (m, $10 \mathrm{H}), 7.85(\mathrm{~m}, 2 \mathrm{H}), 8.39$ (d, 1H), 8.85(d, 1H). ${ }^{13} \mathrm{CNMR}\left(d_{6}\right.$-DMSO, 400mHz): 68, 78, 108, 122, 123, 124, 124.5,
$125.3,127,127.6,129,131,132,135.2,136,139,148,155,156$, 163.

6.16. 4-methoxybenzyl(((5-(1-(4-(trifluoromethyl) phenyl)-1H-tetrazol-5-yl)quinolin-8-yl)oxy)methyl) carbamate (10e). (Figure 4n)

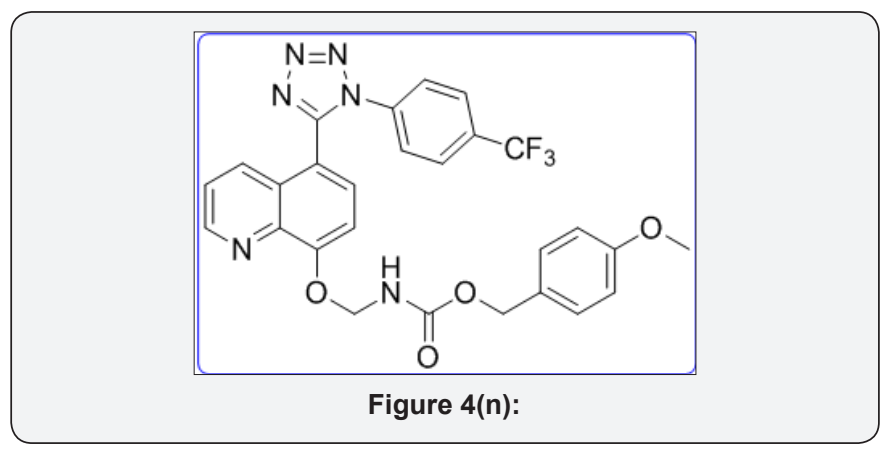

M.P.320-323 ${ }^{\circ} \mathrm{C}$, IR (KBr, cm-1): 3460, 3050, 1640, 1370,785, 665. ${ }^{1} \mathrm{HNMR}\left(d_{6}\right.$-DMSO, $\left.400 \mathrm{mHz}\right): 3.83(\mathrm{~s}, 3 \mathrm{H}), 4.9(\mathrm{~s}, 2 \mathrm{H}), 5.65$ (s, 2H), 6.9-7.1 (m, 5H), 7.55-7.62 (m, $5 \mathrm{H}), 7.85(\mathrm{~m}, 2 \mathrm{H}), 8.38$ (d, 1H), $8.87(\mathrm{~d}, 1 \mathrm{H}) .{ }^{13} \mathrm{CNMR}\left(d_{6}\right.$-DMSO, $\left.400 \mathrm{mHz}\right): 56,67,76,108$, $115,122,123,123.8,124,124.1,125.3,128,129,130,131.9$, $132,135.2,139,149,154,156,158,164$

Step 10: 3-(((5-(1-(4-(trifluoromethyl)phenyl)1H-tetrazol-5-yl)quinolin-8-yl)oxy)methyl) urea derivative (11): (Figure 4o)

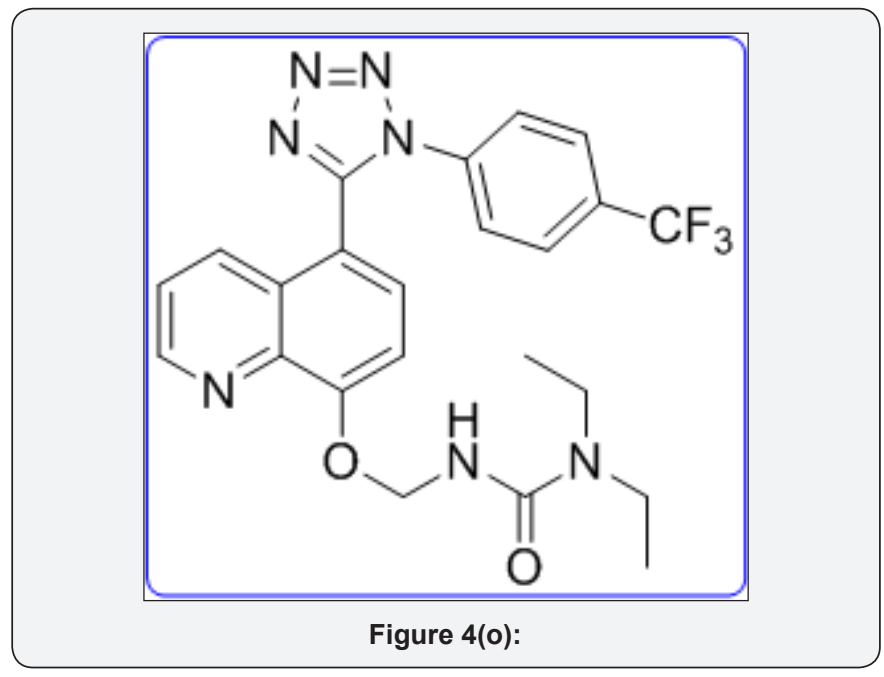

To a solution of 2-((5-(1-(4-(trifluoromethyl)phenyl)1H-tetrazol-5-yl)quinolin-8-yl)oxy)acetyl azide (9) (250 mg, $0.568 \mathrm{mmol}$ ) in Dry toluene $(10 \mathrm{~mL})$ was added Amine (1.3eq) and heated at $100^{\circ} \mathrm{C}$ for $5 \mathrm{~h}$ in sealed tube $(50 \mathrm{~mL})$. The progress of reaction was monitored by TLC. After completion, reaction was evaporated under vacuum to give crude product. The crude was purified by Combi-flash column chromatography (100-200 mesh silica, Eluent: (5-10\% $\left.\mathrm{MeOH}-\mathrm{CHCl}_{3}\right)$, isolated 1-(((5-(1-(4-(trifluoromethyl) phenyl)-1H-tetrazol-5-yl) quinolin-8-yl)oxy )methyl) urea derivatives 11 (a-e). The list of urea derivatives was mentioned in Table 2. 
Table2: The summary of urea derivatives 11(a-e).

\begin{tabular}{|c|c|c|c|c|c|}
\hline Compounds 11(a-e) & $11 a$ & $11 b$ & 11c & 11d & $11 \mathrm{e}$ \\
\hline $\mathrm{R}$ & $\mathrm{H}$ & & & & $\mathrm{P}-\mathrm{MeO}-\mathrm{C}_{6} \mathrm{H}_{4}-\mathrm{NH}_{2}$ \\
\hline Reaction Time & $6 \mathrm{~h}$ & $10 \mathrm{~h}$ & $8 \mathrm{~h}$ & $6 \mathrm{~h}$ & $3 \mathrm{~h}$ \\
\hline Yield & $60 \%$ & $40 \%$ & $55 \%$ & $45 \%$ & $64 \%$ \\
\hline
\end{tabular}

1,1-diethyl-3-(((5-(1-(4-(trifluoromethyl)phenyl)-1Htetrazol-5-yl)quinolin-8-yl)oxy)methyl) urea (11a): IR (KBr, $\mathbf{c m}^{-1}$ ): (Figure 4p)

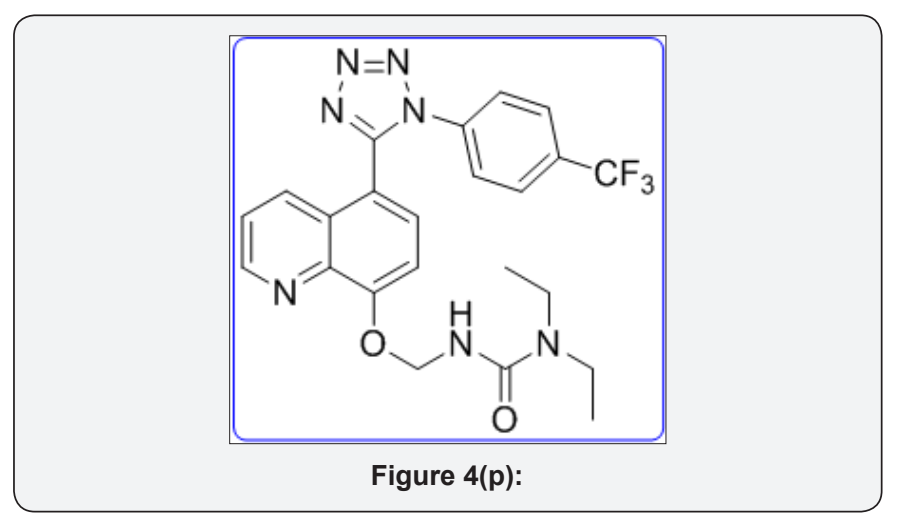

White solid, IR (KBr, $\left.\mathrm{cm}^{-1}\right): 3410,3010,1730,1655,1450$, 1320,780, 650, ${ }^{1} \mathrm{HNMR}\left(d_{6}\right.$-DMSO, $\left.400 \mathrm{mHz}\right): 1.5(\mathrm{t}, 6 \mathrm{H}), 3.8(\mathrm{q}$, $4 \mathrm{H}), 5.4(\mathrm{~s}, 2 \mathrm{H}), 7.15(\mathrm{~d}, 1 \mathrm{H}), 7.5-7.6(\mathrm{~m}, 5 \mathrm{H}), 7.8(\mathrm{~m}, 2 \mathrm{H}), 8.38$ $(\mathrm{d}, 1 \mathrm{H}), 8.8(\mathrm{~d}, 1 \mathrm{H}) \cdot{ }^{13} \mathrm{CNMR}\left(\mathrm{d}_{6}\right.$-DMSO, 400mHz): $15,45,78,108$, 122, 123, 124, 124.5, 125, 131, 132, 135, 139, 149,155,157, 164.

11,1 - diisopropyl-3 - ( ( (5- (1 - (4-(trifluoromethyl) phenyl)-1H-tetrazol-5-yl)quinolin-8-yl)oxy) methyl) urea (11b): IR (KBr, cm${ }^{-1}$ ): (Figure 4q)

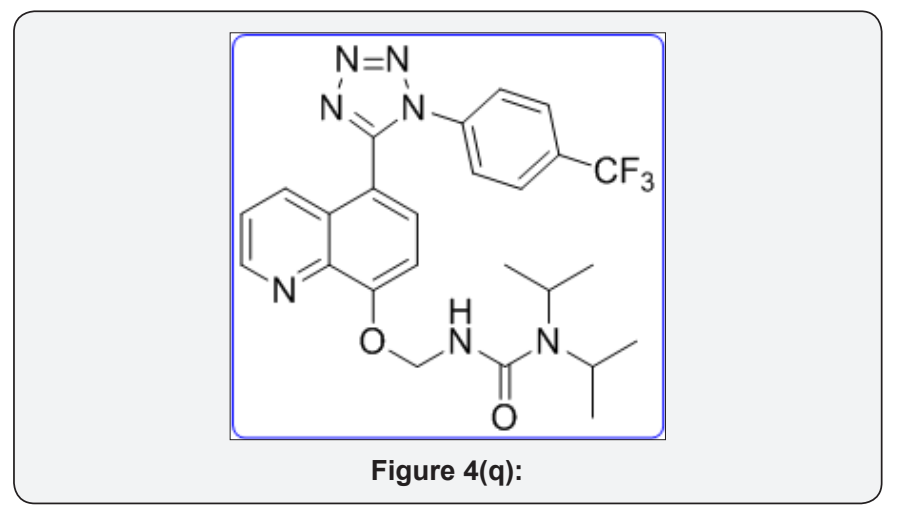

Off white colour solid, IR (KBr, cm-1): 3430, 3020, 1720, 1645, 1440, 1330,760, 640. ${ }^{1} \mathrm{HNMR}\left(d_{6}\right.$-DMSO, 400mHz): $1.4(\mathrm{~d}$, $12 \mathrm{H}), 3.8(\mathrm{q}, 2 \mathrm{H}), 5.6(\mathrm{~s}, 2 \mathrm{H}), 7.1(\mathrm{~d}, 1 \mathrm{H}), 7.5-7.6(\mathrm{~m}, 5 \mathrm{H}), 7.8(\mathrm{~m}$, $2 \mathrm{H}), 8.4(\mathrm{~d}, 1 \mathrm{H}), 8.83(\mathrm{~d}, 1 \mathrm{H}) .{ }^{13} \mathrm{CNMR}\left(\mathrm{d}_{6}\right.$-DMSO, $\left.400 \mathrm{mHz}\right): 21$, $55,77,107,121,123,124,124.5,131,132,133,135,139,148$, 154, 158, 165.

61-(tert-butyl) - 3 - (( (5- (1 - (4-(trifluoromethyl) phenyl)-1H-tetrazol-5-yl)quinolin-8-yl)oxy) methyl) urea (11c): IR (KBr, $\mathbf{c m}^{-1}$ ): (Figure 4r)

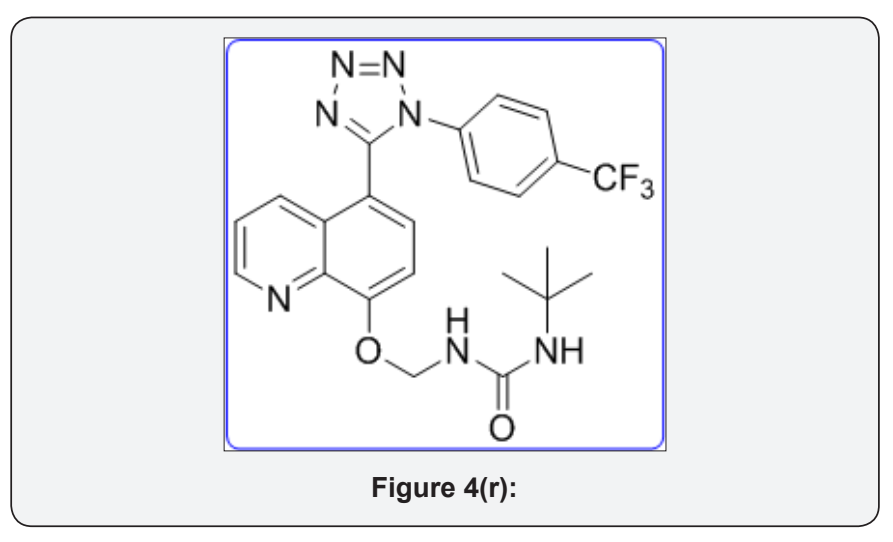

White colour solid, IR (KBr, cm${ }^{-1}$ ): 3460, 3040, 1650, 1460, 1380, 680, 620. ${ }^{1} \mathrm{HNMR}\left(d_{6}\right.$-DMSO, $\left.400 \mathrm{mHz}\right): 1.5(\mathrm{~s}, 9 \mathrm{H}), 5.68(\mathrm{~s}$, $2 \mathrm{H}), 7.15(\mathrm{~d}, 1 \mathrm{H}), 7.5-7.6(\mathrm{~m}, 5 \mathrm{H}), 7.8(\mathrm{~m}, 2 \mathrm{H}), 8.1$ (brs, $1 \mathrm{H}), 8.43$ $(\mathrm{d}, 1 \mathrm{H}), 8.84(\mathrm{~d}, 1 \mathrm{H}) .{ }^{13} \mathrm{CNMR}\left(d_{6}-\mathrm{DMSO}, 400 \mathrm{mHz}\right): 30,58,76$, $108,122,123,124,124.5,131.8,132,133,135,139,146,155$, $157,164$.

1-Cyclopropyl-3-(((5-(1-(4-(trifluoromethyl)phenyl)1H-tetrazol-5-yl)quinolin-8

(11d): IR ( $\left.\mathrm{KBr}, \mathrm{cm}^{-1}\right)$ : (Figure $4 \mathrm{~s}$ ) yl)oxy)methyl)urea

pale yellow colour solid, IR (KBr, $\left.\mathrm{cm}^{-1}\right): 3510,3430,3040$, 1650, 1460, 1340, 690, 550. ${ }^{1} \mathrm{HNMR}\left(d_{6}\right.$-DMSO, 400mHz) : 0.9 $(\mathrm{t}, 2 \mathrm{H}), 1.1(\mathrm{t}, 2 \mathrm{H}), 2.5(\mathrm{~m}, 1 \mathrm{H}), 5.7(\mathrm{~s}, 2 \mathrm{H}), 3.8$ (brs, 1H), 7.15 $(\mathrm{d}, 1 \mathrm{H}), 7.5-7.6(\mathrm{~m}, 5 \mathrm{H}), 7.81(\mathrm{~m}, 2 \mathrm{H}), 8.3(\mathrm{brs}, 1 \mathrm{H}), 8.4(\mathrm{~d}, 1 \mathrm{H})$, 8.80(d, 1H). ${ }^{13} \mathrm{CNMR}\left(d_{6}\right.$-DMSO, 400mHz): 8, 30, 76, 108, 122, $123.1,123.5,124,125.3,130.1,132,135,139.1,149,155,157$, 164.

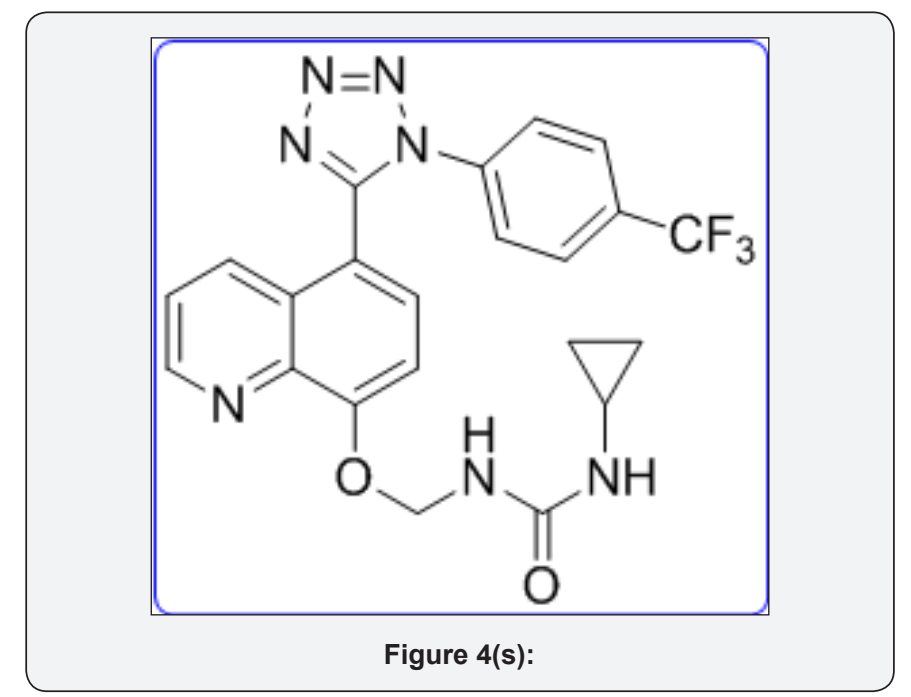


1-(4-methoxybenzyl)-3-(((5-)(1-(4-(trifluoromethyl) phenyl)-1H-tetrazol-5-yl)quinolin-8-yl)oxy)methyl) urea (11e): (Figure $4 \mathrm{t}$ )

White colour solid, IR (KBr, $\left.\mathrm{cm}^{-1}\right): 3540,3430,3030,1640$, 1440, 1350, 730, . ${ }^{1} \mathrm{HNMR}\left(d_{6}\right.$-DMSO, $\left.400 \mathrm{mHz}\right): 3.6(\mathrm{~s}, 3 \mathrm{H}), 4.2$ (s, 2H), $5.7(\mathrm{~s}, 2 \mathrm{H}), 6.8(\mathrm{~d}, 2 \mathrm{H}), 7.1(\mathrm{~d}, 1 \mathrm{H}), 7.25(\mathrm{~d}, 2 \mathrm{H}), 7.5-7.6$ $2(\mathrm{~m}, 5 \mathrm{H}), 7.83(\mathrm{~m}, 2 \mathrm{H}), 8.25$ (brs, 1H), $8.41(\mathrm{~d}, 1 \mathrm{H}), 8.84(\mathrm{~d}, 1 \mathrm{H})$. ${ }^{13} \mathrm{CNMR}\left(d_{6}\right.$-DMSO, $\left.400 \mathrm{mHz}\right): 45,56,77,107.5,115,121,122$, $123,124,130,130.5,130.8,132.2,135,140,149,155,157,158$, 163.

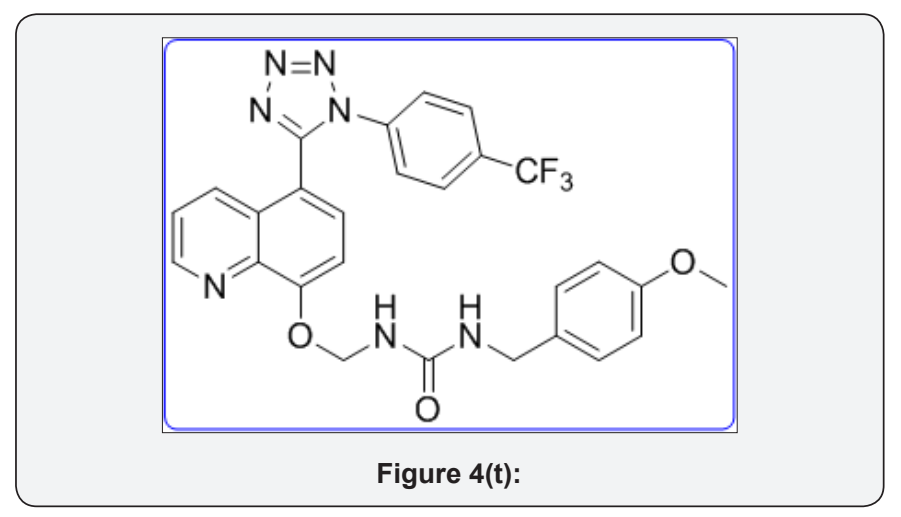

\section{Conclusion}

Present research work we have developed a novel route for synthesis of high potential pharmacological carbamate and urea derivatives using conventional and scalable route. We avoid by products in curtius rearrangement by using dry toluene and reactions were executed under argon atmosphere. We avoid hazard reagents like (phosgene and acid chloride methods) for preparation of urea and carbamate derivatives. We employed very easiest method for preparation of urea and carbamate derivatives and avoid side products. We are planning to these derivatives check for biological evolution. The biological evolution details will include next journal.

\section{Acknowledgement}

I sincerely thankful to my guide (Dr LK Ravindranath), co-workers, Department of Chemistry, Sri Krishnadevaraya University, (Anantapur, Andhra Pradesh, India ) and Gvk Bio sciences for providing laboratory and analytical facilities.

\section{References}

1. Vijaya BV, Rama MH, Hari NP (2014) A Review on Synthesis of Antihypertensive Sartan Drugs. International Journal of Pharma Research \& Review 3(11): 46-56.

2. Maruthamuthu, Shameela R, Christina RSP, Bharathi DAG, Ranjith R (2016) The chemistry and biological significance of imidazole, benzimidazole, benzoxazole, tetrazole and quinazolinone nucleus. Journal of Chemical and Pharmaceutical Research 8(5): 505-526.

3. Rajendran M, Devapiriam D (2015) Journal of Chemical and Pharmaceutical Research 7(1): 763-773.
4. Maria D, Anu M, Jayanthi M, Damodar KS, Raja S (1982) Synthesis Characterization, Antibacterial \& Anti-Inflammatory Effects Of Substituted Tetrazole Derivatives Based On Different Types Of Carbazone And Benzaldehyde. International Journal of ChemTech Research 5(4): 1982-1990.

5. Bhaskar VH, Mohite PB (2010) Synthesis, characterization and evaluation of anticancer activity of some tetrazole derivatives. Journal of Optoelectronics and Biomedical Materials 2(4): 249-259.

6. Kale MA, Peharkar MR (2013) Synthesis of some novel tetrazole substituted benzimidazoles and their evaluation as antioxidants. International Journal of Pharma and Bio Sciences 4(4): 675-681.

7. Davood H, Hiva N, Mahmoud N (2013) Silica Sulfuric Acid as an Efficient Heterogeneous Catalyst for the Solvent-Free Synthesis of 1-Substituted 1H-1,2,3,4-Tetrazoles. Journal of Chemistry 2013: ID645313.

8. Cheng-Xi Wei, Ming B, Guo-Hua G (2015) Tetrazolium Compounds: Synthesis and Applications in Medicine. Molecules 20(4): 5528-5553.

9. Fatemeh D, Shima $\mathrm{K}$ (2015) $\mathrm{FeCl}_{3}$ Catalyzed One Pot Synthesis of 1-Substituted 1H-1,2,3,4-Tetrazoles under Solvent-Free Conditions. International Journal of Organic Chemistry 5(1): 75-80.

10. Venkataraman S, Jason SK, Sangram P, Lynne A, Scott AC, et al. (2015) Design, synthesis, and biological evaluation of tetrazole analogs of $\mathrm{Cl}-$ amidine as protein arginine deiminase inhibitors. Journal of Medicinal chemistry 58(3): 1337-1344.

11. Ostrovskii VA, Trifonov RE Popova EA (2012) Medicinal chemistry of tetrazoles. Russian Chemical Bulletin, International Edition 61(4): 768-780.

12. Mohite PB, Bhaskar VH (2011) Potential Pharmacological Activities of Tetrazoles in The New Millennium international. Journal of PharmTech Research 3(3): 1557-1566.

13. Ivanildo Mangueira da Silva, João da Silva, Filho Priscila Brandão Gomes da Silva (2014) Synthesis and Antimicrobial Activities of 5-Arylidenethiazolidine-2,4-dione Derivatives. Med Research international 2014: 316082 .

14. Sharghia H, Khalifeha R, Moeinia F, Beyzavia MH, Salimi Benic A, et al. (2011) Mannich reaction of secondary amines, aldehydes and alkynes in water using $\mathrm{Cu} / \mathrm{C}$ nanoparticles as a heterogeneous catalyst. J Iran Chem Soc 8: S89-S103.

15. Archana K, Neha K (2016) Synthesis and evaluation of 2-aryl substituted benz imidazole derivatives bearing 1,3,4-oxadiazole nucleus for antimicrobial activity. Der Pharmacia Lettre 8(12): 143148.

16. Andreea-Teodora P, Maria A, Lenuta P (2016) Chem Cent J 2016: 10.6

17. Faiyazalam MS, Navin BP, Dhanji R (2013) Indian jounal of pharmacy and Biotecnology. In: Narasimaha R et al. (Eds.), IJRPB, Andhra Pradesh, India, pp. 1- 496.

18. Devprakash, Udaykumar AB (2011) A complete review of thiazolidine4-ones. Journal of Pharmacy Research 4(7): 2436-2440.

19. (1990) European Journal of Medicinal chemistey 25(7): 569-579.

20. Bhaviskar BA, KhadabadiSS, Deore SL (2013) Synthesis and Evaluation of Some New Thiazolidin-4-One Derivatives as Potential Antimicrobial Agents. Journal of Chemistry (2013): 656271.

21. Tribhuvan S (2014) Synthesis and Evaluation of Thiazolidine-4-One for their Antibacterial Activity Deepak Khobragade. JPSBR: 4(1): 110-113.

22. Kishan DP, Chhaganbhai N P, Grishma M (2016) Med Chem 2016: 6:10. 


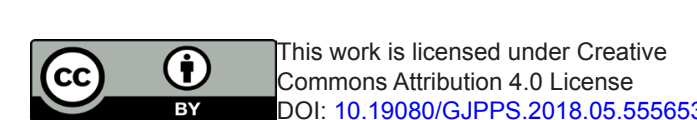
Commons Attribution 4.0 License

BY DOI: 10.19080/GJPPS.2018.05.555653
Your next submission with Juniper Publishers will reach you the below assets

- Quality Editorial service

- Swift Peer Review

- Reprints availability

- E-prints Service

- Manuscript Podcast for convenient understanding

- Global attainment for your research

- Manuscript accessibility in different formats

( Pdf, E-pub, Full Text, Audio)

- Unceasing customer service

Track the below URL for one-step submission https://juniperpublishers.com/online-submission.php 